\title{
The Optimization of Ergonomic / Human Factor Principles in Housing Design: A Literature Survey
}

\author{
Kingsley Okechukwu Dimuna Monoyeren Emmanuel Orits Omatosne \\ Department of Architecture, Ambrose Alli University, Ekpoma, Nigeria
}

\begin{abstract}
The nexus between ergonomic (human factor) and housing design and occupants' satisfaction is essential for housing quality. The need for housing that is comfortable, functional, safe and decent cannot be over emphasized. These can be realized with the application of ergonomic / human factor principles in housing design. This paper examined the critical issues that promote the application of ergonomic/ human factor principles in housing design. They include the following: Comfort and Efficiency in housing design, Users' participation in building designs; the role of ergonomic / human factors in architectural design and the relationship between ergonomic / human factors in sustainable housing designs. The paper made use of library research method, which involved critical review of related literature relevant to the study. The articles were analyzed descriptively. Suggestions that would help in the realization of human factors in housing designs and construction were made. The paper concludes that occupants' satisfaction could be increased and enhanced when architects and other professionals in the built environment give adequate consideration to ergonomic / human factor principles in their building designs.
\end{abstract}

Keywords: Ergonomics, Human factors, housing design, Occupants'Satisfaction and housing quality.

DOI: $10.7176 / \mathrm{JEES} / 9-4-09$

Publication date: April $30^{\text {th }} 2019$

\subsection{Introduction}

Housing has been described as the totality of the immediate physical environment, largely man-made, in which families live, grow and decline (Agbola, 2005). In the same vein, Melnikas (1998) cited by (Henilane,2015) notes that housing is a particular and comparatively limited, physical, biologically, socially close place where people and groups of people can live their biosocial life by receiving services, performing house chores and other biosocial actions.

Three basic necessities of life are always identified for humans- housing, food and clothing. Housing is further identified in the Maslow's hierarchy of needs as a key pillar in that it protects man from weather and predators. The house in fact provides the base from which the family life that eventually aggregate to build the community life, is organized and structured (UNCHS, 2001). Housing is a unit of the environment. In this context, it is able to influence in very diverse ways, the living patterns and social lives of the individual as well as community at large (Akinbode, 2000; Osuide, 2004; Agbola, 2005; Olotuah, 2007; \& Egunjobi, 2007). It also provides safety, warmth and place to rest (Henilane 2015). The World Health Organization (WHO, 1998) recognized the imperative of housing and thus states that the mental and physical health of the people is better when they have appropriate housing. It further establishes that appropriate housing enables the people to have time and bonding with the communities to secure the human needs of psychology, safety and security, a place to physically call a 'home' and hence have cultural base. In all thereafter with appropriate housing in place the individuality of a people are easily determined and expressed for proper health actions. There is therefore a general agreement on the effect of adequate housing on human well-being. Housing means everything to man and its place in overall well-being of the individual, families and nations; is very essential. The importance of housing in life of individuals and families particularly wives, children and the elderly who spend more time in the home than in any other single space demand that occupants' satisfaction in its production be given serious consideration (Gbakeji, 2014; \& Dimuna, 2017). Achieving this goal requires building designs and planning of housing layouts that will manifest suitable living environment and also promote residential satisfaction. This is so because as observed by Chudoba (2014) to stay healthy, a human being needs light, sun, air and warmth in his abode, as well as chances to move about in fresh air and natural surroundings. Only a well planned housing and well designed buildings can guarantee these qualities. To optimize housing quality there is therefore the need for the application of ergonomic or human factor principles in building design.

Ergonomics (also known as human factor) has been defined by the International Ergonomics Association, IEA (2014) as:

"The scientific discipline concerned with the understanding of interactions among humans and other elements of a system. It is the profession that applies; theory, principles, data and methods to design in order to optimize human well being in the overall system performance."

The (New English Dictionary and Thesaurus, 2000) describes ergonomics (also known as human factor) as the study of the interaction between people and their working environment with the aim of improving efficiency. 
Simply put, ergonomics (human factor) therefore entails working to put together the environment that functions in a way that appears natural to people (Health and Safety Executive, HSE, 2007). Ergonomics as a science strives to bridge the gap between man and his surroundings. It takes interest in how people are fitted to their work place and living environment. Ergonomics considers people first by looking into their capabilities and limitations. By so doing, it ensures that responsibilities, tools, information and the surroundings go well with each user and are very interdependent (HSE, 2007).

Ergonomics principle encourages designing for maximum comfort, efficiency, safety and ease of use both in both the work place and the living environment. The goals of design and planning which include efficiency in planning and design, appropriateness in design, structural efficiency and economic use of resources for the improvement of housing quality; are in line with ergonomic principles. Dimuna (2011) notes that most of the inconveniences that lead to dissatisfaction in most living and working environment experienced in the urban and rural built environment could be attributed to poor housing designs and inadequate layout of buildings. These result in non-functional designs manifested in lack of day lighting, poor ventilation, poor circulation, poor project conceptualization and uneconomic use of resources, which lead to cost- overrun and abandonment. All these factors are known to contribute to architectural failures. Awotona (1990) cited by Dimuna (2011), posits that housing design and planning should give adequate consideration to factors such as: (i) livability of dwelling; (ii) sense of community; (iii) aesthetics; (iv) responsiveness to context and flexibility; (v) maintenance; (vi) child supervision and; and (vii) security. These, when considered in building designs, will help to fulfill ergonomic / human factor principles. The application of ergonomic principles is not a new phenomenon though not very popular. Ergonomic principles have been used according to (HSE, 2007) to evaluate many aspects of a person's physical characteristics, such as: body size and shape; fitness and strength; posture; sense, especially vision, hearing and touch; and the stresses and strains on muscles, joints, nerves. It also examines the psychological aspects of a person, such as: mental abilities; personality; knowledge; and experience. Attaianese \& Duca, (2012) observe that despite the fact that human factors are important considerations in the design of built environments, not much research has been done in the import of ergonomic concepts on design methodology. The dearth of available design data and methodology on the subject call for remedies to the problem. This paper seeks to examine the critical issues to be considered in the application of ergonomics or human factors principles in building designs; with a view to analyzing their importance in achieving better and optimal building designs and hence occupants' satisfaction.

\subsection{Literature Review}

The Institute for Occupational Ergonomics (1999) cited by Temple \& Adams (2000) describes ergonomics as an understanding of the needs, limitations, and capabilities of people, and the use of this understanding for the design of products and environments in which people live. This is so, because as observed by Emmitt (2001), whatever technologies, means and processes utilized in the design, assembly and use of building, the entire process involves people.

Housing which include dwelling units and other ancillary facilities and infrastructures ( Akinbode,2000; \& Olatubura, 2007) are designed, detailed, scheduled, assembled, maintained, refurbished, dismantled, used and misused by people (Emmitt, 2001). The human scale therefore is important from design perspective, although, these aspects are over and over again overlooked in favour of new technologies and in favour of aesthetic. Ideally, people should be the strongest link in the housing quality chain instead of making them the weakest chain (Emmitt, 2000). Ergonomic principles advocates that things designed for human use should be made comfortable and efficient for the user.

Historically, "ergonomics" was gotten from two Greek words "ergon" which connotes work and "nomos" which connotes "laws" (IEA, 2000). Ergonomics known as human factors in North America is a subdivision of science that seeks to discover in relation to human abilities and limitations and then relate that understanding to advance people's interactions with products, systems and environments. Ergonomics in the past was unusually thought in terms of products. However, it is by the same token valuable in the design of services or processes. It is used in design in several multifaceted approaches. Ergonomics come up to everything which involves people, such as work system, sports, and leisure. Health and safety issues are important consideration in the application of ergonomic principles. Ergonomists are known to make use of information about people, for instance their size (height, weight, reach, etc) their capacity to handle information and make decisions, their capability to see and hear and their ability to work in excessive temperature (IEA,2014). Ergonomics applies information about human behaviours, capabilities, and restriction and other characteristics to the design of tools, machines, tasks, jobs and environments of productive, safe, comfortable and effective human use (Sanders \& McCormick, 1993). The factors that contribute to human factors are: body posture, and movement (sitting, standing and lifting). Ergonomics as a science strives to bridge the gap between man and his surroundings (Kramer, 2011). Ergonomics has been credited to making work better and therefore essential. It has also been noted for making things comfortable and efficient. 
Previous studies have investigated the use of ergonomic principles in a variety of disciplines, including its application in production engineering, military hardware engineering, occupants' health, safety risk management, production of personnel protective equipments and other related issues in the workplace and residential housing. In recent times attention in the use of ergonomic / human factor principles in architectural design are gaining global attention.

Previous studies on ergonomic or human factor principles have shown that the principle has been used to carry out:

(i) post occupancy evaluation of both occupied administrative, institutional and residential buildings;

(ii) generation of architectural design data;

(iii) identification of ergonomic features relevant to the ability of persons with disability to work and function independently; and

(iv) Evaluation of the impact of ergonomics in the work places.

For instance, Heerwagen \& Zggreus (2005) carried out a post occupancy evaluation of Philip Merril Environment Centre, Annapolis, MD USA. The study investigated the effect of air quality, day lighting, the amount of light and access to views, psychosocial outcome and acoustical conditions. The findings of the research revealed that occupants were highly satisfied with the centre in terms of the listed variables.

In another study (Markova \& Hatiar, 2012) investigated the impact of sustainable ergonomic programme on the basic conditions on corporate social responsibility. The study found out that the technique and technology has significant impact on the employees, and their work environment. The study recommended that sustainable ergonomic programme should focus on three key issues:

(i) Impact of technique and technology to employees at work;

(ii) Creation of work environment in relation to environmental sustainability; and

(iii) Importance and impact of socially responsible human relation (hr) in ergonomics.

In other studies, (Attaianesse, 2011) also used human factor principles to assess the impact of maintenance on sustainable built environment. The study assessed how socio-technical system interaction can be improved in consideration to physical, cognitive and organization aspects of maintenance. The findings revealed that increased processes of sustainability will lead to effectiveness and efficiency, safety and well-being of different parameters involved and lead to environmental sustainable maintenance. In the same vein, (Attaianese, 2013), examined how human factors can be used in the design of sustainable buildings. The study concluded that human factor principles will improve building design, enhance its sustainability performance during all phases of building cycles. In another study (Attaianese \& Duca, 2012) investigated how ergonomic/ human factor principles could be applied in building design. The findings revealed that the ergonomic principles are good tools to enhance architectural design, optimize human contacts with the system, in order to ensure that humans use the "well-organized space" in comfort and safety for occupants' full satisfaction.

Another study (Dimirel \& Duffy, 2012) has shown that ergonomic standards in the work place promote workers' productivity, safety and health. Ergonomic principles have also been used to enhance production of personal protective equipment (PPE).

Previous studies, (Story, Muller \& Mace, 1998) recognize seven ergonomic design principles for interior spaces to include:-

i. Equitable use: the design is of use and saleable to people with diverse abilities.

ii. Flexibility in use: the design contains a wide range of individual liking or inclination and aptitude.

iii. Simple and intuitive use: use of the design is comprehensible, regardless of the user's familiarity, knowledge, current attentiveness level.

iv. Perceptible information: the design communicates necessary information efficiently to the user, regardless of ambient conditions or the user's sensory abilities.

v. Tolerance for error: the design reduces risks and the adverse consequences of accidental or unintended actions.

vi. Low physical effort: the design can be used effectively and at ease, and with a minimum of exhaustion.

vii. Size and space for approach and use: appropriate size and space is provided for approach, reach, manipulation, and use, regardless of the user's body size, posture, or mobility.

This approach to design according to the authors seeks to create environment that are "usable by all people to the greatest extent possible". These principles are in line with architecture which Mcginty \& Gatzke (1997) cited by Dimuna (2011) see as the enhancement of activities of the occupants and users such that the item of size and functionality of the house products are well spelt out through designed arrangements of the building envelope and internal space definition and control with regards to acoustics and room ambiance.

\subsection{Critical issues for Discussions.}

The ergonomic principles or human factors are widely applicable in building design to enhance functionality and housing quality. Attaianese \& Duca (2010) advocated that ergonomic or human factor principles should be 
incorporated in the building design process because of the significant roles they play in the architectural design development. The authors opined that this would help to define a design methodology that would generate functioning and dwelling units suitable for the requirements of residents. The human centered building design method according to (Attaianese \& Duca, 2010); if fully adopted would lead to an interactive procedure for architectural design actions together with human factors ideology, such as:-user's involvement, their variability and diversity consideration, stereotypes and standards, system oriented approach.

From architectural design perspective, there is significant relationship between ergonomics and anthropometrics. Anthropometrics could be describes as the direct measurement of the human body and reach characteristics data of persons such as stature, waist, girth, weight for design purposes. These have been found useful in certain kinds of research. The understanding of these aspects of design principles is very important in architectural education, hence it is taught early in design process and training. However, ergonomics is more than this. Therefore, the critical issues to look into would include: comfort and efficiency, user participation in design, ergonomics and building design, ergonomic and sustainable building and thermal comfort in buildings.

A. Comfort and Efficiency in Design

One of the utmost features of design efficiency is comfort. Physically, comfort while using an item augment its value, while efficiency refers to impressively making tasks easier to do. Efficiency comes in various varieties:

i. Reducing the effort needed makes a course of action more physically efficient- a gentle slope in staircase for example, a continuous monolithic floor slab, without step down.

ii. Reducing the procedures in a task makes it faster (i.e. Efficient) to complete; and

iii. $\quad$ Reducing the number of parts makes repairs more efficient.

Efficiency can be found almost everywhere when it becomes uncomplicated to do things we can accomplish more. Therefore, utility is the true measure of the quality of design. From the architectural design perspective, ergonomic simply refers to principle of designing for maximum comfort, efficiency, safety and ease of use. Therefore, an ergonomic principle is not limited to industrial design but both residential and institutional building typologies. This will help to ensure adequate ventilation and lighting in the living areas and that there is high level of efficiency in institutional typologies especially in work activity areas.

B. Users Participation in Design

One of the key features of ergonomics is the lively participation of end-users'. The International Standard Organisation (1999) recommends that human-centered design of systems should be based on a comprehensible perceptive of the attributes of the users and the general undertaking the dwellers will be engaged with the structure. In the workplace environment, (Nagamachi, 1995) cited by Attainesse \& Duca (2010), posits that the participation of users means the organized use of participatory technique contained by the ergonomics involvement and enquiry, considered a very potent technology of ergonomics for realizing worker's welfare in the workplace environment.

In building design perspective, (Attaianese \& Duca, 2013) note the norm of getting the user to participate in the decision making process has enlarged in the last thirty years. In the field of architectural design however, the line of distinction between users/clients views and the designer's concept has not allowed the ease of adopting wholeheartedly this growing concepts because of the bane of having to water down artistic and socialistic nature of the architectural inputs. Similarly, Volker and Prins (2005) aptly explain that because of the artistic and creative nature of architecture, user participation during the design stage or process cannot really guarantee a design success; while user exclusion invariably results in dissatisfaction. In the same vein, Brown (2001) asserts that it is not appropriate for the user to take part in the design process, because involvement of certain user groups at certain design stages can be counterproductive. However, (Fakere, Arayela \& Folorunso, 2017), advise that building designers must ensure that users' satisfaction with their houses is met as much as possible.

C. Ergonomics (Human Factors) and Architectural Design

(Attaianese \& Duca, 2010) explained that in the diverse fields of architecture, variety of factors such as finance, economics, technical, socio-cultural and aesthetics considerations all have implication in project delivery. Volker \& Prins (2005), as well as (Suckle 1980) summarized by stating the obvious assignments to the design team, which is carried out design problem setting and solving in the concerted attempts to harmonize all these fields of varieties to one single functional entity. Dimuna (2011) further explains the spectrum of architecture, by stating that the architect is expected to be concerned with creation of an environment that will be comfortable for man.

In the content of this discussion, Attainesse \& Duca (2012) thereafter identified four main areas of investigations in the field of ergonomics. These are outlined as follows:

(a) Ergonomics and Building Sustainability, (b) Usability Measurements for Buildings, (c) Buildings Accessibility and Design for all and (d) Building use in Design Management perspective

In architectural design, the closest relationship to ergonomics is anthropometrics. Anthropometrics could be described as the science of collecting body and reach characteristics data of persons for design purposes. Anthropometry deals with the determination and effective utilization of spaces, shapes and sizes for human needs. It plays a useful role by determining the minimum space requirement for each activity within a house such 
as toilets, baths, kitchen, eating, living and leisure, and resting and sleeping. Good understanding of architectural design process is very important in articulating optimal design solutions. Designing in architecture involves the identification of the problems (brief or programme); a method or process of transformation (the design process); and the graphic presentation of imagined future-state (the design solution). Architectural design is the creative process used to translate the problems, needs and aspiration of potential building owners and users into drawings and other documents that depict possible answers to the needs and aspirations and eventually translate them into buildings (Encyclopedia of American Architecture).

Dimuna (2007), states that the rationale of architecture is to provide organization to definite feature of our setting. This means that architecture organizes and manages the relationship connecting an individual and his environment for the comfort of mankind. To achieve this requires making rational decisions.

Design is a conceptualization process; it is primarily a thinking and decision-making process. Decisionmaking in architectural design, as in many other fields of design and planning is concerned with narrowing the field search in the universe of possible design solutions which optimize the return on the clients' investment (Maver, 1973). Olotuah (2009) states that the primary concern of architecture is the promotion of an orderly development of the human environment with particular regards to effective shaping, reordering and articulation of the built environment. This is because the quality of the human habitat is the central issue in architecture. Astrolabe (2002) also asserts that good architecture ought to assure a trinity of requirements for a user, such as his physical needs (satisfactory body reaction or feeling), his emotional needs (atheistic and emotional) and his intellectual needs (logic, order and faultlessness); for this reason architecture appears to be both an art and a science.

D. Ergonomics and Sustainable Building

A number of researches have established the theory that an environment-friendly building design cannot neglect the reality that building occupants are part of the built environment. Therefore a good building from an environmental approach should also be adequate, safe, decent and comfortable for its residents (Hedge 2008). Charytonowicz (2007) posit that through application of ergonomics, the design process can actually assist and smoothen out its process and attempts at selection of the appropriate technologies for optimal design and construction process. This ensures the full optimization of the potentials and attributes of the object of design.

The Ergonomic/Human Factor Principles are widely applied in building designs to enhance sustainable housing designs. Sustainable building design is an approach to architectural design that accentuates the position of buildings with both local ecosystem and global environment. It varies from the microcosm (a psychological idea) of designing bits and pieces for daily utilization through the macrocosm of designing buildings, cities, and earth's physical surface. Sustainable design aims at enhancing the quality of human life while living within the carrying capacity of supporting ecosystems.

The concept of sustainable housing design is predicated on three pillars, these are environmental, cultural and economic. The focus of ergonomic principles on sustainability therefore suggests that the design should be:

i. Environmentally sustainable by ensuring ecosystem integrity, reduce waste, effluent generation, emission to the environment; reduced (negative) impaction on fauna and flora health; and use of renewable raw materials for construction (Hui, 2002).

ii. Culturally relevant and valuable in the sense of maintenance of cultural diversity, valued practices currently existing in the region and building individual citizenship and complete social integration with a culture (Cunha and Cunha, 2005). For a design to be culturally sustainable, it essentially must reflect the culture of its users so because according to Chukwuali (2005) culture and tradition should define the architectural identity of the people. For this reason, Chukwuali (2010) advocates that in the sphere of building design; culture should be given a more specific aesthetic interpretation to describe the intellectual and artistic achievement of a society.

iii. Economically sustainable, on this third tripod, the focus here is that the economic realities of the Nation should be reflective of the types of housing construction, operation and maintenance costs (Oluigbo, 2012). It is in line with this that Gilkinson \& Sexton (2007) emphasize the importance of affordability as a key requirement of sustainable housing.

Ergonomic/Human factors approach is intended to optimize human relations with housing schemes, so as to ensure that human activities are more well-organized, safe, comfortable and satisfying. The residential environment has been described as an active process of human engagement with the surrounding landscape (Chukwuali, 2008). Built environments on daily basis control people's life, due to the fact that all human activities are carried out in the built environment (Attaianesse, 2012). Consequently, architectural design is capable of being enriched by considering principles of human factors, as it provides the cultural and practical situation to predict how technical resolution is able to suit the environmental needs drawn from residents' life and work activities residents carry out. 


\section{E. Thermal Comfort in Buildings}

Thermal comfort according to (Corgnati, Gameiero Da Silva, Asadi, Costa, Filippi \& Kaczmarcyk, 2011) relates to human satisfactory perception of the thermal environment. It alludes to the state in which majority of occupants feel comfortable with space occupied by them either as dwelling or work space. Thermal comfort is an important indicator for determining occupants' comfort and their levels of satisfaction with their indoor environment (Millennium Ecosystem Assessment, 2005). Thermal comfort can be viewed as the state of mind that conveys contentment with the thermal environment and is appraised by subjective evaluation (Edokpolor, 2018). In the same vein, (Fang, Nyon, Clausen \& Fanger, 2004) posit that the human body can be looked as a heat engine where food is the input energy. The human body is known to produce excess heat during physical activities into the environment; the heat transfer in this process is relative to temperature difference. Fadamiro (2015) is of the view that the problem in providing a thermal environment that is comfortable for users is ensuring that the rate at which heat is generated by the body equals that rate at which it is lost to the environment. Although this is the desirable, it does not give the whole picture about how the thermally comfortable environments are achieved. Maintaining standard balance of thermal comfort for building inhabitants and users; therefore, is an important human factor consideration in building design the challenge faced by most building designers in the tropical environment is providing adequate ventilation in habitable spaces such as living rooms, dining rooms, bedrooms and kitchens, balconies; while in the temperate environment trapping heat escape or loses from indoor environment. This calls for energy efficient building design.

Fang et al (2004) posit that majority of people feel comfortable at room temperature range of $20^{\circ} \mathrm{c}$ to $20^{\circ} \mathrm{C}$ $\left(68^{\circ} \mathrm{f}\right.$ to $\left.72^{\circ} \mathrm{f}\right)$, but note that this vary to a great extent between individuals and depending on factors such as activity level, clothing worn and moisture level.

Energy-efficient buildings are only effective when the occupants of the buildings are comfortable. Discomfort will make them seek for alternative means of heating in the temperature or cooling a space in the tropics with air conditioners or other mechanical means.

Thermal comfort is linked with the nature of the material either soft, smooth surface. Consequently, from architectural perspective design should be seen to adopt principles that are flexible and encourage designing naturally ventilated buildings especially in the tropical environment. Such buildings are likely to reduce energy consumption and have potential to enhance satisfaction level of occupants (Frontczak \& Wargocki, 2011).

F. Ergonomics (human factors) and sustainable building design.

According to World Development Report (2003), sustainable development is in relation to people and how the people relate among every one. It is about our habitat abode and its structure of existence. It is also about our desires for richness and preservation. The report further posited that any serious attempt at reducing poverty requires sustainable economic growth in order to increase productivity and income in developing countries.

A school of thought would argue that sustainability merely refers to types of development that are economically viable, do not harm the environment, and are socially just. Whatever the point of view, sustainable development concepts therefore encourage frugal use of renewable and non-renewable resources. Sustainable design according to (Cahill, 2008, ) can be described as the art of designing physical objects to comply with the principles of economic, social and ecological sustainability.

Sustainable building design aims at improving the quality of human life while living within carrying capacity of supporting ecosystems. Sustainable design is context specific and cannot be borrowed therefore it is impossible to develop a universal strategy for sustainable housing design (Ebsen \& Ramboll, 2000). The delivery of sustainable housing remains a great challenge; however, this challenge is more severe in developing countries. While most developed countries have made great strides in evaluating and developing strategies to address this, many developing countries appear largely to borrow or adopt foreign concepts of sustainable housing. According to Oluigbo (2012) to address this lapse, there is need for each society to prioritize its own specific objectives of sustainable housing design. Sustainable development is found on two conception; the concepts of needs encompassing of the circumstances for sustaining an acceptable standard of life for all the populace; and the concept of limits of the capacity of the environment to fulfill the wants of the current and the upcoming generations without compromising the ability of the future generations to meet theirs (World Commission of Environment and Development, 1987; Hui, 2002).

The pillar-based approach to sustainability highlights three issues which must be considered. These are: economy, culture and environment. The economic dimension focuses on viability and economy of cooperation. The cultural dimension focuses on respect for diversity and preservation of diverse cultural heritage. The environmental dimension focuses on respect for local and global environment (Oluigbo, 2012).

Sustainable design encourages the use of local resources (in the form of building materials), use of appropriate and responsive building technologies to meet housing and construction needs of a people. Adams (2004) opined that there is strong grass root ability for innovations in the use of building materials, in some settlements and developments especially in developing countries, with the adaption of sustainable design goals. 


\subsection{Recommendation}

Based on the foregoing, the paper recommends as follows:

I. There is the need to design buildings that are safe, comfortable and functional to its occupants and users. To ensure this, buildings should be designed with due consideration for adequate room sizes, proper ventilation, adequate lighting, floor slabs without step down, staircases without handrail are necessary because step down though may be aesthetically pleasing to the eye but is inconveniencing to the elderly. Handrails are necessary in staircases to ensure balance for users especially the elderly. Good architecture should aim at satisfying the physical needs, aesthetic and psychological needs and intellectual needs of its users (Astrolabe, 2002). The buildings should create an environment and buildings that satisfy the physical and psychological needs of the occupants. The physical needs include comfort in terms of adequate space and room sizes, adequate lighting and ventilation, noise free or low noise level. While the psychological needs manifest in pleasant surroundings and serene environment.

Adequate use landscape elements can enrich the built environment and gratify a number of the emotional desires of the general population, in a neighbourhood. Visual pleasure relaxes a worrying mind and aid long life. The psychosomatic impacts of a pleasurable landscape are substantial and help in nurturing a spirit of neighbourhood belonging, community satisfaction, mixing and delight. High-quality landscape is an influential instrument to realize a pleasing setting. Landscaping add to visual contentment, which has a deep outcome on the emotional life of an individual. Apart from the environment, outstanding architecture of an edifice is another cause of visual fulfilment and pleasure. Therefore should be encouraged (Dimuna, 2011).

II. From the foregoing, Ergonomic Principles dwelt on efficiency and comfortable, these can be translated in architecture to mean efficient utilization of space; good planning.

- Efficient Utilization of Space - In architecture, space is perceived as an entity, a material substance that can be shaped or molded. The character of space is the result of conscious logical design defined by the elements of building form.

- Good planning in architecture refers to the efficient economic arrangement of space. This can be achieved in most building typologies by reducing circulation space.

- Efficiency in architectural design will mean firstly, the logical relationships of parts of functional areas are closely related with the structure. Second is to ensure proper circulation and reduction of distances traversed to minimums. Third, each activity in the building is located in the parts of building most appropriate for it (Dimuna, 2012).

III. There is the need to ensure active participation of users in the architectural design process. The user or potential building owners could be more engaged at the preliminary design stages and working drawing stages to make their input. The building designer should also fully understand the characteristics and attributes of potential occupants to avoid architectural design failures that could lead to occupants' dissatisfaction with the buildings. Hamlin (1952) postulates that in order to make a good plan, therefore, the architect must develop a deep sense of what people are and how they react. He must become a dramatist; he must be able to see his projects building with the eyes of all the various people who will enter it: As observed by Dimuna (2011), Architecture is an integrated art, and in solving any design problem, the architect should always consider the three important parts of architecture, function or use, construction (structural stability) and effect.

IV.

There is the need to give due consideration to anthropometric. The use of anthropometric is vital for success of architectural designs. Therefore, consideration should be given to users and occupants' characteristics including body sizes, strength and mental capability. Due consideration should be given to foreseeable operating conditions including exists in case of emergencies and the elderly and the disable in all buildings especially the public buildings. Consideration should also be given to the interface buildings. Consideration should also be given to the interface between occupants and the building. Equipment including furniture, sanitary wares such as bath tops, water closets should be designed in accordance with key ergonomics/human factors standards.

\subsection{Conclusion}

This study set out to critically review the factors that are germane in the application of ergonomic (human factor) principles in housing design. This is with a view to identifying and examining the critical issues that when considered in the design process would help to enhance and enrich building designs and hence increase occupants' satisfaction. The paper drew attention to the fact that consideration of human scale and human factors in building designs are essential to achieving occupants' satisfaction. The review demonstrated that ergonomics approach to design would help to create an environment that would be usable to both able and disable people, due to its emphases on addressing human limitations and capabilities. The ergonomic principles have the advantage of ensuring frugal use of resources in order to maximize the potentials of architectural building 
designs with a view to ensure that are comfortable, effective, eco-friendly and sustainable. The paper concludes that should this principles and approaches made more visible to architects and other professionals in the built environment, our urban centers will be adorn with buildings that do not pose dangers or hazards to its occupants and enhance housing quality and occupants' satisfaction.

\section{References}

Abe, R., \& Kato, H (2017). Built Environment Travel and Residential satisfaction in a Deveoping City: can Residents under Rapid Urbanization agree with sustainable Urban Form? Asain Travel studies 4 (3) 481498.

Adams, A. K. (2004). The Use of Materials for Tropical Buildings. Anabey Press. India PP204 211

Agbola. T. (2005): "The housing debacle". Inaugural lecture delivered at the University of Ibadan, August 2005.

Akinbode A. (2000): Provision of Adequate Housing in Developing Countries: A Theoretical Consideration in Osuide S.O. (Ed.) Proceedings of the National Seminar on Population Growth Architecture and the Environment $21^{\text {st }}-22^{\text {nd }}$ February, 2000. $109-118$.

Attaianese E. \& Duca G. (2010) Human Factors and ergonomic principles in building design for life and work activities: an applied methodology. Theoretical issues in Ergonomic science. Vol. 13, No. 2 March-April 2012, 187-202. Taylor \& Francis Group

Attaianese E. \& Duca G. (2012), Human Factors and Ergonomic principles in building design for life and work activities: an applied methodology. Theoretical issues in Ergonomic Science, 13(2) 187 - 202.

Attaianese E. (2011). A broader consideration of Human Factor to enhance sustainable building design.

Attainaese E. (2011). Human factors in maintenance for a sustainable management of built environment in J. Lind-fors J, M. Savolainen and S. Vayrynen (Eds.) Wellbeing and innovation through ergonomic. Proceedings of NES 2011 Oulu, September, 18-21, 2011, PP 129-134

Attainese E. and Duca G. "Theoritical issues in Ergonomics Science Vol. 13, No. 2, March-April 2012, 187-202. Awotona A.A. (1990). Nigerian Government participation in housing 1970-1980. Habitat International,14(1).

Brown, Z. B. (2009). Occupant comfort and engagement in green buildings: Examining the effects of knowledge, feedback and workplace culture, $\mathrm{PhD}$ Thesis, submitted to the University of British Columbia, Vaneouver, Canada, 2009.

Charytonowicz J., Reconsumption and Recycling in the Ergonomic Design of Architecture. Universal Access Lecture Notes in Computer Science (Human-Computer Interaction. Ambient Interaction), Vol 4555, (2007) pp. 313-322. (18)

Chudoba M. (2014): Designing Cities, Planning for People: Proceedings of the $6^{\text {th }}$ Annual Architectural Research Symposium in Finland 2014: Designing and planning the built environment for human well-being.

Chukwuali, C. B. (2018), today as the tomorrow we designed for yesterday: the dialectics and modernity in contemporary architecture in Nigeria. $139^{\text {th }}$ Inaugural Lecture Series. University of Nigeria.

Corgnati, S. P., Gameiro da Silva, M., Ansaldi, R., Asadi, E., Costa, J. J., Filippi, M., Kaczmarczyk, J., Melikov, A. K., Olesen, B. W., Popiolek, Z., \& Wargocki, P. (2011). Indoor climate quality assessment - evaluation of indoor thermal and indoor air quality. Rehva Guidebook, 14. Brussels: Rehva.

Cunha, S. K. \& Cunha J. C. (2005). Tourism Cluster Competiveness and Sustainability: Proposal for a Systemic Model to Measure the impact of Tourism on Local Development. Brazilian Administration Review. 2(2): 47-62.

Dimirel, H. O. \& Duffy V. G. (2013), A sustainable human centered design framework based on human factors. Springertink, part of Springer Science + Business media. 80 (25) $307-315$.

Dimuna K. O (2007) Architectural Design, a determinant of housing quality, Journal of environmental research digests. Vol. 2, No.2, July 2007

Dimuna, K. O. (2011). The social effects of the built environment: a case study of selected buildings in Benin City, Nigeria. Journal of Human Ecology, 34(3): 189-196 (2011)

Dimuna K. O. (2017): A Study of Residents' Satisfaction with Public Low Cost housing estates in Benin City, Edo State, Nigeria. Unpublished PhD Thesis submitted to Department of Architecture, AAU, Ekpoma, April 2017.

Edokpolo L. O., (2018). Investigation of the influence of landscape on thermal comfort in the tropics: A case study of Benin City, Nigeria. A Seminar paper presented to the Department of Architecture, Amrbose Alli University, Ekpoma, 30 July, 2018.

Emmitt S. (2002).: Architectural Technology; EPP Books Service, Blackwell Publisher Ltd. Oxford. Pp 10-12.

Encyclopedia of America Architecture, Hunt Publishers New York.

Fadamiro, J. A. (2015). Behavioral Architecture. Graams Print, Lagos Nigeria.

Fakare, A. A, Aruyela O., \& Folorunsho, C. O, Nexux between the participation of residents in house design and residential satisgaction in Akure, Nigeria. Frontiers of Architectural Research (2017) 6, $137-148$.

Fang, L., Wyon, D.P., Clausen, G., \& Finger, P. O. (2004). Impact of indoor air temperature and humidity in an 
office on perceived air quality, SBS symptoms and performance. Indoor air. 14 (7), 74-81.

Gbakeji J. O. (2014): Analysis of residential satisfaction in some neighbourhoods in Benin City, Nigeria. Journal of Civil and Environmental Engineering, 2 (1), 1 - 10.

Gilkinson, N. \& Sexton, M. (2007). Delivering Sustainable Homes; Meting Requirements: A Research Agenda, Proceedings of XXXV IAHS World Congress on Housing Science, Melbourne, Australia, 4-7 September, CD-ROM.

Hamlin T. (1952).: Forms and Functions of Twentieth Century Architecture. Vol II. In Talbot Hamlin (ed), Columbia University Press, Columbia.

Health and Safety Executive, (HSE, 2007). Understanding ergonomics at work. www.hsebooks.co.uk retrieved January, $25^{\text {th }}, 2011$.

Hedge A., (2008). The Sprouting of “Green” Ergonomics. HFES Bulletin 51:12 (2008) pp. 1-3. (13).

Heerwagen J. \& Zagreus L (2005). The Human Factors of Sustainable building design: Post occupancy evaluation of the Philip Merrill Environmental Centre, Amapoles, MD USA. Report prepared for: Drum Crawley U.S. Department of Energy, Building Technology program.

Henilane, I (2016): Housing Concepts and Analysis of Housing classification. Baltic Journal of Real Estate Economics and Construction Management. 4, 168-179. November, 2016.

Hui, C. M. (2002). Sustainable Architecture. Retrieved September $10 \quad 2007$ from http://www.arch.htu/research/BEER/index.html

IEA, (2000). International Ergonomic Association: Triennial report. Santa Monica, CA: IEA Press.

IEA Technical Committee, Human Factors and Sustainable Development retrieved November 12 2010http://www.iea.cc/browse.php?contID=hf and sustainable $\operatorname{dev}(3)$

IEA, (2014). Human Factors and Ergonomic Society. Educational Resources. http://www.usernomics.com/ergonomics-faq.htm

Institute for Occupational Ergonomics (1999). Department of Manufacturing Engineering and Operations Management University of Nottingham UK, http//www.ccc.nottingham.ac.uk/epzwww/Research/ioe/index.html.

ISO 13407, (1999). Human-centred design processes for interactive systems. Geneva: International Standard Organization.

Kramer A. (2011). Seven Principles of Ergonomic Interior Design Tuesday, January, 25, 2011.

Kroemer K.H.E, and Grandjean E, (2000), Fitting the Task to the Human, Taylor \& Francis.

Kromer K. (1994). Ergonomics, how to design for ease and efficiency, New Jersey; Prentice Hall.

Melnikas, B. (1998). Management and modernization of housing facilities: specific features of central and eastern European countries. Facilities, 16 (11), 326-333.

Millennium Ecosystem Assessment. (2005). Ecosystems and Human Well-Being: Synthesis. Washington DC: Island Press.

Nagamachi, M., 1995. Requisites and practices of participatory ergonomics. International Journal of Industrial Ergonomic, 15 (5), 371-377.

Olatubara, C.O. \& Fatoye, E.O. (2007). Evaluation of the satisfaction of occupants of the Abesan public low-cost housing estate in Lagos State, Nigeria. The Nigerian journal of Economic and Social Studies 49 (1).

Olotuah O.A, (2009) Demystifying the Nigerian Urban Housing Questions (53 ${ }^{\text {rd }}$ Services of Inaugural Lecture; Federal University of Technology, Akure, $10^{\text {th }}$ March 2009, page 38-40.

Oluigbo S. N. (2012). Prioritising Architectural Design Objectives for Sustainable Housing in Nigeria Compilation Seminar Papers of the Architects Colloquium 2012. Architecture and The Nigeria Development Agenda v. On Sustainable Built Environment II. PP246-252

Osuide S. O. (2004): Strategies for Affordable Housing Stock Delivery in Nigeria. $18^{\text {th }}$ Inaugural Lecture Series, Ambrose Alli University, Ekpoma. February 2004. P.1.

Sanders M.S., McCormick J., (1993), Human Factors in Engineering and Design, McGraw Hill Inc: New York

Story, Molly Follette, James L. Muller, Ronald L Mace, The Universal Design File: Designing for people of All ages and Abilities. Design Research and methods Journal 1998. The centre for universal design NC State University.

Suckle, A., (1980). By their own design. New York: Whitney Library of Design.

Temple R. \& Adams T. (2000). Ergonomic Analysis of a Multi-Task Industrial Lifting Station Using the NIOSH Method. Journal of Industrial Technology. 16 (2) 2-6.

UNCHS (2001) An Urbanizing World: Global report on human settlement 2001. Oxford: Oxford University Press.

United Nations Centre for Human Settlements (UNCHS HABITAT) 2001. Millennium Declaration, Paragraph 19.

United Nations Habitat, (2001): Housing, Policy and Development Section (HPDS), Habitat Agenda. Pp. 53.

Volker, L. and Prins, M., (2005). Exploring the possibilities of correlating management with value in 
architectural design. In: Emmit S. and Prins M. eds. Proceedings of the CIB W096 architectural management. 2-4 November, Lyngby, Rotterdam: CIB, 47-59.

WCED (1987). World Commission on Environment and Development, WCED (1987): Our Common Future, Oxford, Oxford University Press.

WHO (1998). The contribution of the World Health Organization to a New Public Health and Health Promotion. (Models for population Health). Geneva, Switzerland. 